CORRECTION

\title{
Correction to: First-person representations and responsible agency in Al
}

\section{Miguel Ángel Sebastián ${ }^{1}$}

Published online: 20 April 2021

(c) Springer Nature B.V. 2021

\section{Correction to: Synthese \\ https://doi.org/10.1007/s11229-021-03105-8}

Due to a mistake at Springer Nature, the article was published online with an incorrect author group. This has been corrected.

The original article can be found online at https://doi.org/10.1007/s11229-021-03105-8.

\section{Miguel Ángel Sebastián}

1 Instituto de Investigaciones Filosoficas, UNAM, Universidad Autonoma de Mexico, Circuito Mtro Mario de la Cueva, Ciudad Universitaria, Del. Coyoacan, 04510 Mexico City, Mexico 